\title{
Pengaruh Penggunaan Paylater Terhadap Perilaku Impulse Buying Pengguna E-Commerce di Indonesia
}

\author{
Received: \\ 10 September \\ 2020 \\ Revision \\ received: \\ 4 November \\ 2020 \\ Accepted: \\ 1 Desember \\ 2020
}

\author{
Rahmatika Sari \\ Jurusan Administrasi Niaga, Politeknik Negeri Bandung, Indonesia
}

\begin{abstract}
:
The development of e-commerce has had an impact on payment methods which were originally only known as cash payments, paper-based, card based, are now being introduced with new electronic-based payment systems such as m-banking, virtual accounts, payment applications. Paylater is a type of online credit payment. Paylater allows its users to have a credit card without a card and without a complicated manufacturing process. This study uses a quantitative descriptive analysis method so that the data used is the result of distributing questionnaires to 404 samples who meet the criteria. The results of this study indicate that the ease of use oftechnology paylaterhas an effect of $6.4 \%$ on the impulsive buying behavior ofusers $e$-commerce in Indonesia. From the results of data processing, it can be concluded that the ease of use oftechnology paylater byusers e-commerce in Indonesia is very good andusers paylater tend to make impulse buying when shopping.
\end{abstract}

Keywords: e-commerce, online impulse buying, paylater

\begin{abstract}
Abstrak:
Perkembangan e-commerce memberikan dampak pada metode pembayaran yang semula hanya dikenal pembayaran tunai, berbasis kertas, berbasis kartu, kini mulai diperkenalkan dengan sistem pembayaran baru berbasis elektronik. Paylater merupakan salah satu jenis pembayaran kredit secara online. Penggunaan paylater tersebut diperkirakan dapat menjadi salah satu pemicu terhadap perilaku impulse buying, oleh karenanya penelitian ini dilakukan dengan tujuan untuk mengukur sebesar apa pengaruh dari penggunaan paylater tersebut terhadap perilaku impulse buying pengguna e-commerce di Indonesia. Penelitian ini menggunakan metode analisis deskriptif kuantitatif sehingga data yang digunakan merupakan hasil dari penyebaran kuesioner terhadap 404 orang sampel yang memenuhi kriteria. Hasil dari penelitian ini menyebutkan bahwa kemudahan dalam penggunaan teknologi paylater memberikan pengaruh sebesar $6,4 \%$ terhadap perilaku pembelian impulsif pengguna e-commerce di Indonesia. Dari hasil pengolahan data dapat disimpulkan bahwa kemudahan dalam penggunaan teknologi paylater oleh pengguna e-commerce di Indonesia sangat baik sekali serta pengguna paylater cenderung melakukan impulse buying saat berbelanja.
\end{abstract}

Kata kunci: e-commerce, online impulse buying, paylater

\section{Pendahuluan}

Pada tahun 2020 teknologi telah berkembang sangat signifikan. Perkembangan tersebut memberikan dampak yang sangat besar kepada dunia, salah satunya dalam sektor niaga. Teknologi membuat 
berniaga menjadi jauh lebih mudah. Masyarakat yang semula membeli barang secara offline, kini dimanjakan dengan banyaknya pilihan kemudahan dalam berbelanja secara online, seperti dengan adanya e-commerce.

Hadirnya e-commerce telah membuat perubahan pada perilaku konsumen yang semula hanya berbelanja secara offline dengan datang langsung ke pusat perbelanjaan, pasar, maupun toko itu sendiri sekarang dapat dengan mudah dilakukan secara online di rumah. Perubahan perilaku tersebut banyak dipengaruhi oleh persepsi para pelanggan mengenai jarak, harga, promosi, tempat yang telah ditetapkan oleh perusahaan selama ini (Kotler dan Keller, 2012). Alasan terbesar terjadinya perubahan pola perilaku pembelian dari pembelian secara langsung ke pembelian online karena dasar kemudahan yang ditawarkan dari toko online, namun kendati banyaknya kemudahan yang ditawarkan masih terdapat faktor-faktor yang menjadi alasan beberapa pelanggan tidak memilih berbelanja online, diantaranya yaitu faktor resiko penipuan baik dari segi kualitas maupun sistem pembayaran (Fakri, 2016).

Pembelian suatu produk dapat terjadi karena konsumen memiliki kebutuhan terhadap produk tersebut yang kemudian dipengaruhi oleh ketersediaan anggaran untuk memenuhi kebutuhan tersebut. Dengan pertumbuhan sistem pembayaran yang saat ini terjadi, tolak ukur ketersediaan anggaran bukan hanya dilihat dari ketersediaan dana dalam bentuk uang tunai saja, namun juga dapat diukur dari bentuk layanan fasilitas seperti kartu kredit ataupun pembayaran digital lainnya (Widawati, 2011).

Sistem pembayaran yang terus berkembang menjadi salah satu faktor pendukung perkembangan e-commerce. Sistem pembayaran yang merupakan salah satu faktor yang menopang stabilitas sistem keuangan saat ini terus berkembang, seperti halnya dengan perkembangan sistem pembayaran yang semula hanya uang tunai hingga saat ini sudah tersedia sistem digital. Metode pembayaran yang disediakan oleh e-commerce mayoritas adalah pembayaran secara digital seperti transfer intra bank, virtual account, kartu kredit online, kartu debit online, $e$-wallet, dll. Namun pembayaran secara tunai juga tetap dapat dijadikan opsi pilihan. Beberapa e-commerce menyediakan pembayaran secara tunai menggunakan sistem Cash On Delivery (COD) dimana pengguna dapat membayar belanjaan secara tunai kepada kurir saat barang diantar. Selain metode cash on delivery, beberapa e-commerce juga menyediakan pilihan pembayaran tunai melalui mini market. Beberapa tahun belakangan ini, tepatnya sejak tahun 2018, terdapat sebuah metode pembayaran baru yang diperkenalkan pada masyarakat, yakni teknologi paylater.

Paylater memiliki fungsi yang sama dengan kartu kredit, kelebihan yang ditawarkan dari teknologi ini ialah cara mendaftar yang relatif sangat mudah jika dibandingkan dengan kartu kredit. Seperti halnya kartu kredit, paylater yang dapat mempermudah konsumen untuk memenuhi segala kebutuhannya, mulai dari berbelanja kebutuhan primer hingga hiburan seperti pembelian tiket pesawat, pemesanan hotel, tiket rekreasi, dan lainnya kemudian pengguna dapat membayar disetiap tanggal jatuh tempo yang sudah ditetapkan.

Paylater dikembangkan oleh perusahaan fintech yang kemudian bekerja sama dengan e-commerce dalam menyediakan layanan paylater tersebut. E-commerce pertama yang memperkenalkan paylater di Indonesia adalah Traveloka dengan menggandeng perusahaan fintech PT. Dana Pasar Pinjaman. Gambar I.2 merupakan produk paylater_yang beredar di Indonesia. Banyak perusahaan e-commerce menggunakan teknologi tersebut dalam sistem pembayaran mereka sehingga teknologi tersebut sangat mudah dikenal oleh masyarakat luas.

Antusias masyarakat dengan hadirnya teknologi paylater dibuktikan dengan meningkatnya jumlah pengguna paylater dari waktu ke waktu. Beberapa platform penyedia paylater telah mengalami lonjakan pengguna yang cukup tinggi. Sejak paylater diluncurkan, Traveloka mengalami lonjakan pengguna hingga 10 kali lipat (Walfajri, 2019), sedangkan e-commerce penyedia jasa layanan transportasi online, Gojek, mengalami kenaikan hingga 14 kali lipat (Fadila, 2020) sehingga mereka harus terus meningkatkan keamanan data pengguna dengan adanya lonjakan tersebut. Platform penyedia lain yang merasakan dampak dari paylater juga ialah Shopee. Hingga tahun 2020, jumlah pengguna Shopee Paylater mencapai angka 1,27 juta pengguna dengan akumulasi borrower yang aktif mencapai $67 \%$ yakni sekitar 850 ribu orang borrower. Jumlah dana pinjaman yang dikeluarkan oleh Shopee Paylater mencapai hampir Rp1,5 Triliun dengan tingkat keberhasilan mencapai hampir 95\% (Lentera Dana, 2020). 


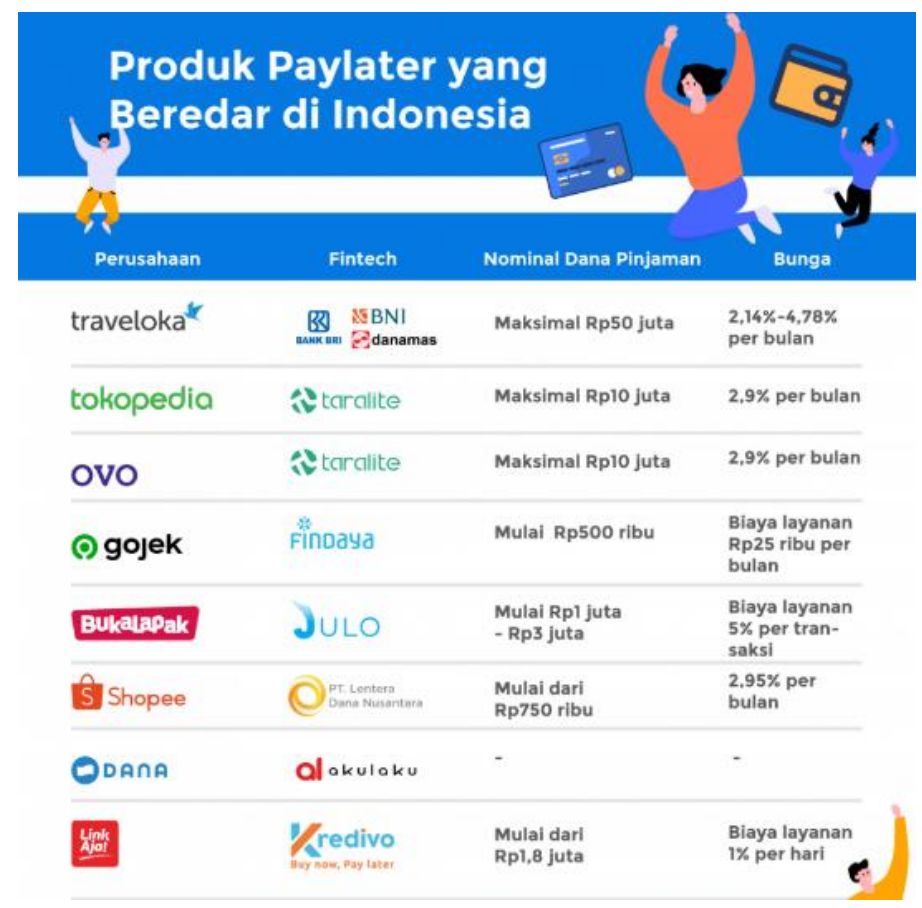

Gambar 1 Produk Paylater di Indonesia

Sumber: Nabila (2020)

Dengan semakin dikenalnya teknologi paylater dapat membuat konsumen sering kali tidak dapat mengabaikan keinginan untuk membeli produk yang menurutnya menarik (Widawati, 2011). Kondisi tersebut dikenal dengan istilah impulse buying. Impulse buying merupakan sebuah perilaku yang dilakukan seseorang ketika membeli produk yang tidak direncakan secara spontan (Rook, 1987). Prinsip kerja dari perilaku impulse buying ini tidak sama dengan model umum keputusan pembelian bertahap karena seseorang yang melakukan impulse buying bahkan tidak mengetahui dasar alasan dari pembeliannya (Widawati, 2011). Impulse buying dapat disebabkan oleh dorongan dari diri pengguna itu sendiri maupun dari faktor lainnya (Harmon dan Novia, 2016).

Lee (2018) mengungkapkan bahwa komponen model penerimaan TAM terutama faktor kognitif dan afektif dapat digunakan untuk memprediksi perilaku impulse buying pada pengguna e-commerce. Penelitian ini akan membahas mengenai penerimaan pengguna e-commerce terhadap sebuah teknologi pembayaran digital baru serta pengaruhnya terhadap perilaku impulse buying. Menurut Rigopoulos (2019) para pelaku bisnis harus selalu beradaptasi dengan inovasi teknologi pembayaran digital terutama dalam industri ritel. Pembahasan topik penerimaan teknologi pada paylater dilakukan karena paylater merupakan sebuah teknologi baru dalam hal pembayaran digital sehingga dengan mengukur pengaruhnya terhadap perilaku impulse buying dapat dijadikan pertimbangan dalam penerapan strategi oleh para pelaku bisnis.

Berdasar pada latar belakang masalah yang telah dijabarkan, tujuan dari penelitian ini adalah (1) mengidentifikasi penerimaan teknologi paylater dalam sistem pembayaran terutama dalam e-commerce di indonesia; (2) mengidentifikasi perilaku impulsif pengguna e-commerce di indonesia; (3) menganalisis pengaruh penggunaan paylater terhadap perilaku impulsif pada pengguna e-commerce di indonesia.

\section{Kajian Literatur}

\section{E-Commerce}

Electronic commerce atau lebih dikenal dengan nama e-commerce jika diartikan secara bahasa berarti perdagangan elektronik. Menurut Laudon dan Traver (2014), e-commerce merupakan transaksi yang terjadi melalui internet, web, ataupun perangkat seluler. Sedangkan menurut Zwass (1996), e-commerce merupakan wadah untuk berbagai informasi mengenai bisnis, menjalin serta menjaga hubungan bisnis, juga tempat untuk menjalankan transaksi bisnis itu sendiri dengan bantuan jaringan telekomunikasi. 
E-commerce juga mencakup berbagai jenis transaksi yang dilakukan secara online, termasuk diantaranya transaksi perbankan online, bisnis ritel secara online, transportasi online, juga berbelanja secara online. Jenis yang dilakukan dalam e-commerce pun beragam mulai dari business-to-business (B2B) hingga consumer-to-business (C2B) (Nayoan, 2019).

\section{Metode Pembayaran Paylater}

Akselerasi pembayaran juga terkena dampak dari perkembangan teknologi, hal tersebut dibuktikan dengan terus meningkatnya sistem pembayaran diseluruh dunia. UU No. 23 Tahun 1999 tentang Bank Indonesia pasal satu angka enam saat ini alat pembayaran yang dikenal selain pembayaran tunai ialah pembayaran berbasis kertas (Cek/BilyetGiro), berbasis kartu (Kartu Kredit dan Kartu Debet) dan berbasis digital. Saat ini masyarakat di Indonesia mulai diperkenalkan dengan sistem pembayaran digital tersebut. Menurut Tarantang et. al (2019) pembayaran digital adalah pembayaran dengan memanfaatkan teknologi. Uang disimpan kemudian diproses serta diterima dalam bentuk informasi dalam pembayaran digital, proses pemindahan uang tersebut dilakukan menggunakan alat bantu pembayaran elektronik.

Pada pertengahan 2018 perusahaan fintech memperkenalkan sebuah teknologi pembayaran dengan konsep cicilan tanpa kartu kredit, yakni Paylater. Saat ini paylater banyak diadopsi oleh e-commerce di Indonesia, mulai dari perusahaan hiburan, pemesanan tiket dan hotel, market place, hingga perusahaan penyedia jasa transportasi online (Nabila, 2020).

Paylater merupakan sebuah alternatif metode pembayaran yang mengadopsi sistem cicilan secara online tanpa memerlukan kartu kredit. Beberapa platform saat ini mulai banyak mengadopsi teknologi cicilan kredit tanpa kartu tersebut (Quiserto, 2019). Paylater pada tahun 2020 ini sudah dapat dinikmati masyarakat dibeberapa platform belanja online, pemesanan tiket dan hotel, hingga transportasi online. Kelebihan Paylater adalah:

1. Proses pendaftaran mudah

2. Diawasi OJK

3. Fleksibel dan cepat

4. Promo khusus

Sementara kekurangan Paylater diantaranya:

1. Bunga cukup tinggi

2. Denda

3. Keamanan data

\section{Persepsi Kemudahan dalam Penggunaan}

Persepsi kemudahan dalam penggunaan ialah tindakan seorang individu yang percaya bahwa dengan penggunaan suatu teknologi tertentu dapat mengurangi usahanya dalam melakukan sesuatu (Davis, 1989). Dalam penelitian yang dilakukan ini, dimensi ini mengacu kepada sejauh mana pengguna merasa bahwa teknologi paylater mudah dalam penggunaan serta sederhana.

\section{Persepsi Manfaat}

Persepsi atas manfaat merupakan tingkat kepercayaan seorang individu bahwa dengan penggunaan teknologi tersebut akan membuat performa pekerjaannya meningkat (Davis, 1989). Seorang individu akan menggunakan sebuah teknologi jika sudah mengetahui manfaat yang mungkin dirasakan ketika menggunakan teknologi tersebut (Thompson, 1991). Pada penelitian yang dilakukan, persepsi kemanfaatan ini mengacu kepada sejauh mana pengguna paylater percaya bahwa penggunaan teknologi ini memiliki manfaat dalam transaksi online.

\section{Intensitas Penggunaan}

Menurut Davis (1989), intensitas penggunaan sebuah teknologi adalah keinginan seorang individu untuk terus menggunakan teknologi. Sikap serta perhatian individu terhadap sebuah teknologi dapat mencerminkan tingkat penggunaan teknologi pada individu tersebut seperti halnya timbul keinginan untuk menambahkan perangkat tambahan dalam teknologi, timbul keinginan untuk mengajak orang lain menggunakan teknologi, dll. (Hanggono, 2015). 


\section{Sikap dalam Penggunaan yang Sesungguhnya}

Penggunaan sesungguhnya dari sebuah teknologi dapat diukur menggunakan frekuensi serta durasi setiap pengguna dalam menggunakan teknologi tersebut (Davis, 1989). Ketika sebuah teknologi mudah digunakan, memiliki manfaat dalam penggunaannya, maka pengguna akan terus menggunakan teknologi tersebut berdasarkan manfaat yang dirasakannya, hal tersebut kemudian dapat menimbulkan kepuasan dari penggunanya (Natalia Tangke, 2004).

\section{Perilaku Impulse Buying}

Pembelian impulsive merupakan kecenderungan konsumen untuk membeli sebuah produk dengan spontan dan segera (Rook dan Fisher, 1995). Sedangkan menurut Baumeister (2002) impulsive buying adalah dorongan yang tiba-tiba datang untuk membeli sebuah produk, pembelian ini tidak terencana atau tidak ada niatan awal untuk membeli, dimana konsumen akan membeli produk atas dasar dorongan tanpa mempertimbangkan akibat jangka panjang dari pembelian. Perilaku impulsive buying terjadi secara mendadak dan individu tersebut tidak dapat menahan hasrat untuk membeli suatu barang walaupun barang tersebut bukan merupakan kebutuhan atau tujuannya. Pada hakikatnya pembelian secara impulsif merupakan perilaku ketika seorang individu meraskan desakan secara spontan agar membeli suatu produk tanpa direncakanan sebelumnya, perilaku tersebut dapat disebabkan oleh dua faktor yang berasal dari diri individu itu sendiri maupun dari pasar (Harmon dan Novia, 2016).

Impulse buying memiliki empat karakteristik, yakni sebagai berikut (Rook dan Fisher, 1995):

1. Spontanitas, perasaan yang dirasakan individu ketika melihat suatu produk kemudian timbul perasaan untuk membelinya pada saat itu juga.

2. Kekuatan, kompulsi, dan intensitas, perilaku membuat keputusan seketika tanpa mempertimbangkan hal-hal lainnya.

3. Kegairahan dan stimulasi, dorongan yang muncul seketika untuk membeli suatu produk yang disertai dengan anggapan produk tersebut memberikan gairah dan stimulasi.

4. Ketidakpedulian terhadap akibat, perasaan untuk membeli produk secara mendesak membuat individu yang merasakannya tidak mempedulikan akibat yang mungkin akan timbul.

Terdapat lima faktor yang memengaruhi pembelian impulsif pada perilaku konsumen (Gunadhi, 2012), yakni:

1) Shopping Enjoyment. Menurut Goyal (2007) merupakan karakter seorang individu yang memiliki kecenderungan menganggap bahwa belanja adalah hal yang menyenangkan dan menggembirakan.

2) Ketersediaan dana menjadi sebuah faktor penting yang memengaruhi perilaku pembelian impulsif (Beatty dan Ferrel, 1998).

3) In-store Browsing, kegiatan mengamati toko oleh konsumen guna mengumpulkan informasi produk maupun sekedar hiburan tanpa ada niat untuk langsung membeli produk-produk yang ada ditoko tersebut (Bloch et.al, 1986).

4) Felt Urge to Buy, perasaan yang mendorong untuk membeli sebuah produk dengan segera (Rook, 1987).

5) Kepemilikan Kartu Kredit. Phau dan Woo (2008) menyatakan bahwa kartu kredit berpengaruh positif terhadap perilaku pembelian impulsif karena perilaku pembelian impulsif tersebut biasanya dilakukan secara tidak terencana dan oleh sebab itu biasanya konsumen tidak memegang uang kontan sehingga menggunakan alat pembayaran lain untuk melakukan transaksi, seperti kartu kredit.

\section{Kerangka Pemikiran}

Berdasarkan kajian teori yang dipaparkan sebelumnya, dapat digambarkan alur pikir mengenai pengaruh paylater terhadap perilaku impulse buying sebagai berikut: 


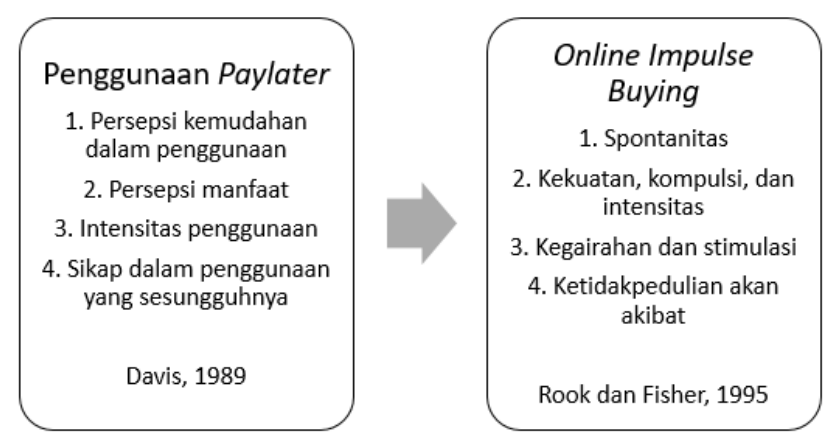

Gambar 2 Kerangka Pemikiran

Sumber: Davis (1989) dan Rook and Fisher (1995)

Penelitian ini mencari pengaruh untuk mengetahui paylater berpengaruh signifikan terhadap perilaku impulse buying, maka hipotesis dari penelitian ini adalah:

$\mathrm{H}_{0} \quad$ : Penggunaan paylater tidak berpengaruh terhadap perilaku impulse buying

$\mathrm{H}_{1} \quad$ : Penggunaan paylater berpengaruh terhadap perilaku impulse buying

\section{Metode Penelitian}

Pada penelitian ini, peneliti menggunakan metode deskriptif kuantitatif, dimana menurut Sugiyono (2013) karena penelitian ini disajikan dengan menggunakan pendapat ilmiah yang bersifat realitas dapat diklarifikasikan, jelas, terukur, dan hubungannya dengan variabel adalah sebab dimana penelitiannya menggunakan angka-angka dan analisis statistik. Subjek yang akan diteliti dalam penelitian ini adalah orang yang pernah menggunakan paylater untuk berbelanja pada platform apa saja yang menyediakan paylater, seperti Traveloka, Gojek, Grab, Shopee, dan lainnya.

Dalam penelitian ini yang termasuk sebagai populasi adalah pengguna yang pernah menggunakan teknologi paylater. Pada penelitian ini populasinya termasuk ke dalam populasi yang tidak terhingga karena tidak diketahui secara pasti jumlah pengguna teknologi paylater pada semua platform penyedia (Harinaldi, 2005). Sampel adalah bagian dari populasi dalam penelitian (Suhartanto, 2014). Adapun yang menjadi sampel penelitian adalah bagian dari populasi yang telah sesuai dengan karakteristik yang dapat mewakili seluruh populasi (Budiasih, 2012). Menurut perhitungan menggunakan rumus Lemeshow, sampel pada penelitian ini minimal 385 orang. Pada penelitian ini, pengumpulan data dilakukan menggunakan media kuesioner online. Kuesioner dalam penelitian ini dibuat secara online menggunakan bantuan google form, tujuannya agar mudah untuk menjangkau sampel secara luas.

Dalam sebuah penelitian yang menggunakan media kuesioner untuk pengumpulan datanya, harus dipastikan bahwa seluruh item kuesioner yang digunakan valid dan reliabel. Uji validitas dan uji reliabilitas baik untuk dilakukan sebelum proses pengumpulan data dimulai. Analisis deskriptif digunakan untuk menganalisis data dimana data-data yang diperoleh dideskripsikan atau digambarkan sebagaimana adanya tanpa ada maksud untuk mengeneralisir (Sugiyono, 2013). Uji Asumsi klasik dilakukan untuk menilai apakah di dalam sebuah model regresi linear Ordinary Least Square (OLS) terdapat masalah-masalah asumsi klasik. Analisis ini adalah sebuah teknik yang dipakai untuk mengetahui hubungan antar variabel yang bersifat kuantitatif. Analisis regresi linier sederhana dilakukan guna mengukur pengaruh yang diberikan dari variabel independen kepada variabel dependen. $\mathrm{R}$ square atau koefisien determinasi dianalisis guna mengetahui sejauh apa kemampuan model dalam menerangkan variasi dari variabel bebas pada penelitian (Ghozali, 2013).

\section{Hasil dan Pembahasan}

\section{Profil Responden}

Dalam penelitian ini responden merupakan orang yang memiliki akun Paylater pada e-commerce di Indonesia. Tabel 1 merupakan informasi karakteristik responden yang meliputi jenis kelamin, usia, pendidikan terakhir, serta pendapatan per bulan.

\section{Tabel 1 Profil Responden}




\begin{tabular}{|l|l|l|l|}
\hline Karakteristik & Kelompok & Jumlah & Persentase \\
\hline \multirow{3}{*}{ Jumlah Transaksi Menggunakan Paylater } & 1 kali & 48 & 11,9 \\
\cline { 2 - 4 } & $2-5$ kali & 135 & 33,4 \\
\cline { 2 - 4 } Subtotal & $>5$ kali & 221 & 54,7 \\
\hline Jenis kelamin & & $\mathbf{4 0 4}$ & $\mathbf{1 0 0}$ \\
\hline & Laki-laki & 75 & 18,6 \\
\hline Subtotal & Perempuan & 329 & 81,4 \\
\hline Usia & & $\mathbf{4 0 4}$ & $\mathbf{1 0 0}$ \\
\hline & $17-25$ tahun & 321 & 79,5 \\
\hline & $26-34$ tahun & 70 & 17,3 \\
\hline & $35-42$ tahun & 8 & 2 \\
\hline Subtotal & $>42$ tahun & 5 & 1,2 \\
\hline Pekerjaan & & $\mathbf{4 0 4}$ & $\mathbf{1 0 0}$ \\
\hline & Pelajar/Mahasiswa & 231 & 57,2 \\
\hline & Wirausaha & 21 & 5,2 \\
\hline & Pegawai Negeri & 15 & 3,7 \\
\hline & Pegawai Swasta & 92 & 22,8 \\
\hline Subtotal & Lainnya & 45 & 11,1 \\
\hline Pendapatan & & $\mathbf{4 0 4}$ & $\mathbf{1 0 0}$ \\
\hline & <Rp1 Juta & 104 & 25,7 \\
\hline & Rp1 Juta-Rp2 Juta & 122 & 30,2 \\
\hline & Rp2 Juta-Rp3 Juta & 48 & 11,9 \\
\hline Subtotal & $>$ Rp3 Juta & 130 & 32,2 \\
\hline & & $\mathbf{4 0 4}$ & $\mathbf{1 0 0}$ \\
\hline
\end{tabular}

\section{Uji Validitas}

Sebelum melakukan penyebaran kuesioner pada setiap responden, dilakukan pengujian validitas kuesioner terhadap 30 orang responden. $\mathrm{R}_{\text {tabel }}$ untuk responden sebanyak 30 orang dengan signifikansi sebesar 5\% adalah 0,3610. Tabel 2 dan Tabel 3 memuat hasil uji validitas pada 30 orang responden.

Tabel 2 Uji Validitas Variabel TAM

\begin{tabular}{|l|l|}
\hline & Corrected Item-Total Correlation \\
\hline Paylater mudah dipelajari & .540 \\
\hline Paylater mudah digunakan & .446 \\
\hline Paylater menyerderhanakan transaksi online & .660 \\
\hline Paylater bermanfaat dalam transaksi online & .628 \\
\hline Paylater membantu transaksi online & .691 \\
\hline Keinginan untuk terus menggunakan & .622 \\
\hline Paylater dapat dikembangkan lagi & .492 \\
\hline Hampir setiap hari menggunakan paylater & .512 \\
\hline Paylater merupakan teknologi yang bagus & .647 \\
\hline JUMLAH VARIABEL PENGGUNAAN PAYLATER & $\mathbf{1 . 0 0 0}$ \\
\hline
\end{tabular}

Kolom Corrected Item-Total Correlation dalam tabel IV.2 menunjukkan nilai seluruh item melebihi $\mathrm{r}_{\text {tabel }}(0,3610)$ sehingga seluruh item pernyataan untuk variabel penggunaan paylater dalam kuesioner ini dinyatakan valid.

Tabel 3 Uji Validitas Variabel Impulse Buying

\begin{tabular}{|l|l|}
\hline & Corrected Item-Total Correlation \\
\hline Sering membeli produk secara langsung & .761 \\
\hline Tidak berpikir sebelum transaksi & .809 \\
\hline Tidak memerhatikan harga & .646 \\
\hline
\end{tabular}




\begin{tabular}{|l|l|}
\hline Mudah tergoda membeli produk baru & .710 \\
\hline Timbul dorongan untuk pembelian tidak terencana & .637 \\
\hline Tidak memikirkan akibat & .661 \\
\hline Perasaan menyesal setelah melakukan transaksi & .551 \\
\hline JUMLAH VARIABEL IMPULSE BUYING & $\mathbf{1 . 0 0 0}$ \\
\hline
\end{tabular}

Kolom Corrected Item-Total Correlation pada tabel diatas menunjukkan nilai pada seluruh item melebihi $r_{\text {tabel }}(0,3610)$ sehingga seluruh item pernyataan untuk variabel $Y$ dalam kuesioner ini dapat dinyatakan valid.

\section{Uji Reliabilitas}

Pengujian reliabilitas dilakukan untuk mengetahui apakah instrument pernyataan yang digunakan untuk mengukur bersifat terpercaya dan konstan. Sesuai dengan tabel standar Cronbach's Alpha, nilai koefisien reliabilitas wajib lebih dari 0,70 untuk menyatakan bahwa item yang digunakan bersifat reliabel. Tabel 4 memuat hasil uji reliabilitas pada 30 orang responden.

Tabel 4 Uji Reliabilitas

\begin{tabular}{|l|l|l|}
\hline \multicolumn{1}{|c|}{ Variabel } & \multicolumn{1}{|c|}{ Cronbach's Alpha } & \multicolumn{1}{c|}{ N of Items } \\
\hline Penggunaan Paylater & 757 & 13 \\
\hline Impulse Buying & 781 & 8 \\
\hline
\end{tabular}

Berdasarkan hasil uji reliabilitas tersebut (Tabel IV.6) nilai koefisien reliabilitas pada kedua variabel $>0.70$ sehingga setiap instrument dalam kuesioner bersifat konsisten dan dapat digunakan berulangulang.

\section{Analisis Deskriptif}

Pada variabel penggunaan paylater, dimensi dengan nilai rata-rata tertinggi adalah persepsi kemudahan dalam penggunaan, sehingga dapat diartikan bahwa pengguna menganggap bahwa paylater mudah digunakan. Sedangkan dimensi dengan nilai rata-rata terendah adalah sikap dalam penggunaan yang sesungguhnya.

Pada variabel impulse buying, dimensi dengan nilai rata-rata tertinggi adalah stimulasi dan kegairah sehingga dapat diartikan bahwa pengguna paylater seringkali merasakan stimulasi tertentu ketika berbelanja menggunakan paylater. Sedangkan dimensi dengan nilai rata-rata terendah adalah spontanitas.

Tabel 5 Analisis Deskriptif Variabel Penggunaan Paylater

\begin{tabular}{|l|c|l|l|l|l|}
\hline & n & Min & Max & Rata-rata & Std. Deviasi \\
\hline Persepsi Kemudahan dalam Penggunaan & 404 & 1 & 5 & 4.44 & .721 \\
\hline Persepsi Manfaat & 404 & 1 & 5 & 4.39 & .784 \\
\hline Intensitas Penggunaan & 404 & 1 & 5 & 4.05 & 1.029 \\
\hline Sikap dalam Penggunaan yang Sesungguhnya & 404 & 1 & 5 & 3.19 & 1.006 \\
\hline $\begin{array}{l}\text { JUMLAH VARIABEL PENGGUNAAN } \\
\text { PAYLATER }\end{array}$ & 404 & 1 & 5 & 4.02 & .885 \\
\hline
\end{tabular}

Tabel 6 Analisis Deskiptif Variabel Impulse Buying

\begin{tabular}{|l|c|l|l|l|l|}
\hline & n & Min & Max & Rata-Rata & Std. Deviasi \\
\hline Spontanitas & 404 & 1 & 5 & 2.32 & 1.101 \\
\hline Kekuatan, Kompulsi, dan Intensitas & 404 & 1 & 5 & 2.51 & 1.094 \\
\hline Stimulasi dan Kegairahan & 404 & 1 & 5 & 3.15 & 1.213 \\
\hline Ketidakpedulian Akan Akibat & 404 & 1 & 5 & 2.77 & 1.167 \\
\hline JUMLAH VARIABEL IMPULSE BUYING & 404 & 1 & 5 & 2.68 & 1.143 \\
\hline
\end{tabular}




\section{Uji Normalitas}

Dalam penelitian ini digunakan analisis grafik Normal Probability Plot (P-Plot). Berdasarkan Gambar 3 dapat dilihat bahwa titik ploting mengikuti dan mendekati sumbu diagonalnya. Sehingga berdasarkan pada pedoman pengambilan keputusan yang telah ditetapkan dapat diambil keputusan bahwa nilai residual dalam pengujian ini berdistribusi normal. Oleh karena itu asumsi normalitas dalam regresi linier sederhana dapat terpenuhi.

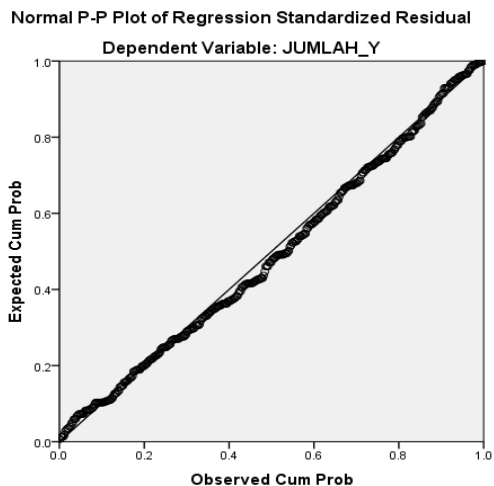

Gambar 3 Uji Normalitas

\section{Uji Linieritas}

Uji linieritas yang digunakan adalah Test for Linearity. Adapun hasil uji linearitas dengan membandingkan rata-rata kedua variabel dapat dilihat pada tabel di bawah ini. Pada tabel 7 tersebut nilai signifikansi linearity adalah 0.000 dan nilai signifikansi dari deviation from linearity adalah 0,007. Hasil tersebut menunjukkan bahwa kedua variabel tersebut berhubungan secara linear.

Tabel 7 Uji Linearitas

\begin{tabular}{|c|c|c|c|c|c|c|c|}
\hline & & & Sum of Squares & df & $\begin{array}{c}\text { Mean } \\
\text { Square }\end{array}$ & $\mathrm{F}$ & Sig. \\
\hline Jumlah & Between & (Combined) & 2514.262 & 35 & 71.836 & 2.546 & .000 \\
\hline Buying $* \mathrm{~J}$ & Groups & Linearity & 824.500 & 1 & 824.500 & 29.221 & .000 \\
\hline $\begin{array}{l}\text { Penggunaan } \\
\text { Paylater }\end{array}$ & & $\begin{array}{l}\text { Deviation } \\
\text { Linearity }\end{array}$ & 1689.762 & 34 & 49.699 & 1.761 & .007 \\
\hline & Within G & & 10383.329 & 368 & 28.216 & & \\
\hline & Total & & 12897.592 & 403 & & & \\
\hline
\end{tabular}

\section{Analisis Kolerasi Sederhana}

Pengujian ini dilakukan guna mengetahui hubungan antar variabel. Metode yang digunakan yaitu korelasi Pearson. Berikut merupakan hasil analisis korelasi Pearson (Tabel 8). Dari Tabel 8 dapat ditarik kesimpulan adanya korelasi antara variabel penggunaan paylater dan variabel impulse buying dalam penelitian ini.

Tabel 8 Analisis Korelasi Pearson

\begin{tabular}{|c|c|c|c|}
\hline & \multicolumn{2}{|c|}{ JUMLAH PENGGUNAAN JUMLAH IMPULSE } \\
\hline & & PAYLATER & BUYING \\
\hline \multirow[t]{3}{*}{$\begin{array}{l}\text { JUMLAH PENGGUNAAN } \\
\text { PAYLATER }\end{array}$} & $\begin{array}{l}\text { Pearson } \\
\text { Correlation }\end{array}$ & 1 & $.253^{* *}$ \\
\hline & Sig. (2-tailed) & & .000 \\
\hline & $\mathrm{N}$ & 404 & 404 \\
\hline \multirow[t]{3}{*}{$\begin{array}{l}\text { JUMLAH IMPULSE } \\
\text { BUYING }\end{array}$} & $\begin{array}{l}\text { Pearson } \\
\text { Correlation }\end{array}$ & $253^{* *}$ & 1 \\
\hline & Sig. (2-tailed) & .000 & \\
\hline & $\mathrm{N}$ & 404 & 404 \\
\hline
\end{tabular}




\section{Analisis Koefisien Determinasi}

Nilai yang dihasilkan dari perhitungan koefisien determinasi dapat menggambarkan besar pengaruh variabel penggunaan paylater terhadap variabel impulse buying. Tabel 9 merupakan hasil perhitungan koefisien determinasi. Pada tabel 9 diketahui bahwa nilai $\mathrm{R}^{2}$ yang dihasilkan adalah 0,064 atau 6,4\%. Hal tersebut berarti bahwa variabel penggunaan paylater berpengaruh sebesar $6,4 \%$ terhadap perilaku Impulse Buying. Sedangkan 93,6\% sisanya dipengaruhi oleh variabel dan faktor lain yang tidak diteliti dalam penelitian ini.

Tabel 9 Hasil Analisis Koefisien Determinasi

\begin{tabular}{|l|l|l|l|l|}
\hline Model & R & R Square & Adjusted R Square & Std. Error of the Estimate \\
\hline 1 & $.253^{\text {a }}$ & .064 & .062 & 5.480 \\
\hline \multicolumn{2}{|l|}{ a. Predictors: (Constant), JUMLAH PENGGUNAAN PAYLATER } \\
\hline \multicolumn{2}{|l}{ b. Dependent Variable: JUMLAH IMPULSE BUYING } \\
\hline
\end{tabular}

\section{Uji Hipotesis}

Pengujian hipotesis yang dilakukan menggunakan Uji T. Hipotesis dalam penelitian ini adalah:

$\mathrm{H}_{0} \quad$ : Penggunaan paylater tidak berpengaruh terhadap perilaku impulse buying

$\mathrm{H}_{1} \quad$ : Penggunaan paylater berpengaruh terhadap perilaku impulse buying

Pada tabel 10 diketahui nilai t hitung adalah 5,240. Sedangkan nilai t tabel dengan df (n-k) sebanyak 402 dan nilai signifikansi 5\% adalah sebesar 1,9658. Dengan demikian maka dinyatakan t hitung $(5,240)>t$ tabel $(1,9658)$. Sesuai dengan dasar pengambilan keputusan dalam uji $t$ hal tersebut berarti bahwa $\mathrm{H}_{0}$ ditolak. Artinya penggunaan paylater berpengaruh terhadap perilaku Impulse Buying.

Tabel 10 Hasil T Hitung

\begin{tabular}{|c|c|c|c|c|c|}
\hline \multirow[b]{2}{*}{ Model } & \multicolumn{2}{|c|}{$\begin{array}{l}\text { Unstandardized } \\
\text { Coefficients }\end{array}$} & $\begin{array}{l}\text { Standardized } \\
\text { Coefficients }\end{array}$ & \multirow[t]{2}{*}{$\mathrm{t}$} & \multirow[t]{2}{*}{ Sig. } \\
\hline & $\mathrm{B}$ & Std. Error & Beta & & \\
\hline 1 (Constant) & 9.075 & 1.776 & & 5.11 & 0.000 \\
\hline $\begin{array}{l}\text { JUMLAH PENGGUNAAN } \\
\text { PAYLATER }\end{array}$ & 190 & .036 & .253 & 5. & 0.000 \\
\hline
\end{tabular}

\section{Pembahasan}

Berdasarkan hasil analisis demografi, 54,7\% responden dalam penelitian ini atau sebanyak 221 orang responden pernah menggunakan paylater untuk transaksi online lebih dari lima kali. Hal tersebut berarti sebagian besar responden dalam penelitian ini berulang kali menggunakan paylater setelah penggunaan pertamanya. Sebesar $81,4 \%$ responden atau sebanyak 329 orang responden berjenis kelamin perempuan. Menurut hasil penelitian Nisa (2013) perempuan lebih sering belanja dibandingkan dengan pria selain itu perempuan memiliki lebih banyak faktor pendukung dibandingkan dengan pria. Rentan usia sebagian besar responden adalah 17 hingga 25 tahun, yakni sekitar 79,5\% atau sebanyak 321 orang dengan status sebagai pelajar atau mahasiswa.

Hasil analisis data menunjukan bahwa penggunaan paylater memberikan pengaruh kepada perilaku impulse buying. Merujuk pada tabel IV.14, berdasarkan hasil uji T hipotesis yang diterima adalah $\mathrm{H}_{1}$ yaitu penggunaan paylater berpengaruh terhadap perilaku impulse buying konsumen pada $e$ commerce di Indonesia. Penggunaan paylater ini berpengaruh sebesar 6,4\% (Tabel IV.13) terhadap perilaku impulse buying. Walaupun pengaruh dari penggunaan paylater terhadap impulse buying cukup sedikit, namun pengaruhnya menunjukkan arah yang positif (Tabel IV.12) sehingga setiap ada penambahan penggunaan paylater sebesar 1 maka perilaku impulse buying pun akan bertambah senilai 0,190 . Penggunaan paylater oleh pengguna e-commerce di Indonesia dapat memberikan pengaruh pada perilaku impulse buying karena pengguna merasakan kemudahan serta manfaat dari teknologi tersebut dalam bertransaksi online. 


\section{Kesimpulan}

Berdasar pada hasil pengolahan data serta analisis yang telah dilakukan, maka dapat diambil kesimpulan yang sekaligus menjawab perumusan masalah dari penelitian ini. Pertama, penggunaan teknologi paylater berada pada kategori sangat baik. Hal tersebut berarti bahwa teknologi paylater yang merupakan sebuah teknologi baru dalam pembayaran digital digunakan dengan sangat baik oleh pengguna e-commerce di Indonesia. Kedua, perilaku impulse buying dari pengguna paylater di Indonesia berada pada kategori cukup tinggi. Artinya bahwa pengguna paylater cenderung masih sering melakukan impulse buying dalam belanja online pada e-commerce. Ketiga, penggunaan paylater tersebut memberikan pengaruh yang positif terhadap perilaku impulse buying. Pengaruh yang diberikan sebesar $6,4 \%$ sedangkan $93,6 \%$ pengaruhnya diakibatkan oleh faktor-faktor lain yang tidak diteliti dalam penelitian ini.

Berdasarkan kesimpulan yang telah disebutkan diatas terdapat beberapa saran yang berhubungan dengan penelitian yang dilakukan dengan maksud memberikan masukan yang positif. Pertama, paylater dapat meningkatkan kualitas layanan yang diberikan kepada pengguna agar pengguna dapat merasakan pengalaman yang lebih menyenangkan ketika bertransaksi online menggunakan paylater. Seperti penetapan bunga yang lebih rendah. Salah satu hal yang dapat menjadi penyebab Paylater memberikan dampak yang tidak terlalu besar kepada perilaku impulse buying, yakni hanya sebesar $6,4 \%$ dapat diakibatkan karena bunga pada paylater yang cukup tinggi serta penetapan denda yang cukup tinggi pula. Kedua, paylater harus memperluas jaringan penggunaannya agar teknologi tersebut tidak hanya dapat dinikmati dalam transaksi online saja namun juga dalam transaksi secara offline sehingga dapat meningkatkan frekuensi, durasi, serta intensitas penggunaan dari teknologi paylater oleh penggunanya, selain itu dapat pula meningkatkan spontanitas konsumen ketika berbelanja.

\section{Daftar Pustaka}

Adhiputra, M. W. (2015). Aplikasi Technology Acceptance Model terhadap Pengguna Layanan Internet Banking. Jurnal Bisnis dan Komunikasi, 2 (1), 52 - 63.

Akram, U., Hui, P., Kaleem Khan, M., Tanveer, Y., Mehmood, K., \& Ahmad, W. (2018). How Website Quality Affects Online Impulse Buying. Asia Pacific Journal Of Marketing And Logistics, 30(1), 235-256. doi:10.1108/apjml-04-2017-0073

Amos, C., Holmes, G.R. and Keneson, W.C. (2014), "A Meta-Analysis Of Consumer Impulsive Buying”, Journal Of Retailing And Consumer Services, Vol. 21 No. 2, pp. 86-97.

Bank Indonesia. (2008). Laporan Sistem Pembayaran dan Pengedaran Uang. Direktorat Akunting dan Sistem Pembayaran dan Direktorat Pengedaran uang.

Beatty, S. E., \& Elizabeth Ferrell, M. (1998). Impulse buying: Modeling its precursors. Journal of Retailing, 74(2), 169-191. doi:10.1016/s0022-4359(99)80092-x

Bloch, Peter H; Daniel L Sherrell and Nancy M Ridgway. (1986). Consumer Search: An Extended Framework, Journal of Consumer Research, 13, (1), 119-26.

Boateng, R., Heeks, R., Molla, A., \& Hinson, R. (2008). E-commerce and socio-economic development: conceptualizing the link. Internet Research, 18(5), 562-594. doi:10.1108/10662240810912783

Budiasih, Yanti. (2012). Statistik Deskriptif untuk Ekonomi dan Bisnis. Tangerang: Jelajah Nusa

Chaffey, D. (2002). E-Business and E-commerce Management. Harlow: Pearson Education Limited.

Davis, F. D. (1989). Perceived Usefulness, Perceived Ease of Use, and User Acceptance of Information Technology. MIS Quarterly, 13(3), 319. doi:10.2307/249008.

Engel, J.F., Blackwell, R.D., Miniard, P.W. (2005). Consumer Behavior 10th Edition. Amerika Serikat: South-Western College Pub.

Fakri, Ahmad. (2016). Pengaruh Online Customer Review Dan Rating Terhadap Kepercayaan Dan Minat Pembelian Pada Online Marketplace Di Indonesia. Surabaya: Institut Teknologi Sepuluh Nopember.

Fearon, C., Philip, G. (1998). Self assessment as a means of measuring strategic and operational benefits from EDI: the development of a conceptual framework. Eur J Inf Syst 7, 5-16. https://doi.org/10.1057/palgrave.ejis.3000287

Ghozali, Imam. 2013. Aplikasi Analisis Multivariate dengan program IBM SPSS 21. Semarang: Badan Penerbit Universitas Diponegoro. 
Goyal, Mittal. (2007). Gender influence on shopping enjoyment-an empirical study. Ind. Manage. Stud. J. 11 (2007), 103-116. DOIURL :http://dx.doi.org/10.18843/ijms/v5i3(5)/02

Gunadhi, Novy. (2012). Faktor-Faktor yang Mempengaruhi Impulse Buying pada Carrefour di Surabaya. Surabaya: Institut Teknologi Sepuluh Nopember.

Hanggono, Aditya Arie. Handayani, Siti Ragil. Susilo, Heru. (2015). Analisis Atas Praktek TAM (Technology Acceptance Model) Dalam Mendukung Bisnis Online Dengan Memanfaatkan Jejaring Sosial Instagram. Malang: Universitas Brawijaya.

Harinaldi. (2005). Prinsip-Prinsip Statistik Untuk Teknik dan Sains. Jakarta: Erlangga.

Harmon \& Novia. (2016). Faktor Penentu Perilaku Impulsive Buying Pada Fashion Business Di Kota Bandung. Bandung: Politeknik Negeri Bandung.

Hendra, J., \& Iskandar R, A. (2016). Aplikasi Model TAM Terhadap Pengguna Layanan Internet Banking di Kantor Bank Jatim Cabang Situbondo. Jurnal Ilmiah Ecobuss, 4(1), 40 - 48. Retrieved from https://ejournal.upm.ac.id/index.php/ecobuss/article/view/203

Hoch, S. J., \& Loewenstein, G. F. (1991). Time-Inconsistent Preferences and Consumer Self-Control. Journal of Consumer Research, 17(4), 492. doi:10.1086/208573

Istiarni, P. R. D., \& Hadiprajitno, P. B. (2014). Analisis Pengaruh Persepsi Manfaat, Kemudahan Penggunaan Dan Kredibilitas Terhadap Minat Penggunaan Berulang Internet Banking Dengan Sikap Penggunaan Sebagai Variabel Intervening (Studi Empiris: Nasabah Layanan Internet Banking di Indonesia). Diponegoro Journal of Accounting, 3(2), 888-897. Retrieved from https://ejournal3.undip.ac.id/index.php/accounting/article/view/6155

Kotler, P., \& Keller, K. L. (2012). Marketing Management. Upper Saddle River, N.J: Pearson Prentice Hall.

Kusnawan, Agus. Silaswarna, Diana. Andy. Tjong, Sefung. (2019). Pengaruh Diskon pada Aplikasi eWallet terhadap Pertumbuhan Minat Pembelian Impulsif Konsumen Milenial di Wilayah Tangerang. Tangerang: Universitas Budi Dharma.

Laudon, Kenneth C.\&Traver, Carol Guercio. (2014). E-commerce: business, technology, society tenth edition. New Jersey: Pearson Education, Inc.,

Lee, H. (2018). Intrinsic and extrinsic motivations affecting impulse-buying tendency in mobile shopping. Social Behavior and Personality: An International Journal, 46(4), 683694. doi:10.2224/sbp.6693

Lemeshow, S. \& David W.H.Jr, 1997. Besar Sampel dalam Penelitian Kesehatan (terjemahan). Yogyakarta: Gadjahmada University Press.

Listfield, Robert. Montes-Negret, Fernando. (1994). Modernizing payment systems in emerging economies (English). Policy, Research working paper ; no. WPS 1336. Washington, DC: World Bank. http://documents.worldbank.org/curated/en/669981468765043216/Modernizing-paymentsystems-in-emerging-economies

Lok, C. K. (2015). Adoption of Smart Card-Based E-Payment System for Retailing in Hong Kong Using an Extended Technology Acceptance Model. Advances in Business Marketing and Purchasing, 255-466. doi:10.1108/s1069-09642015000023b003

Loudon, David L \& Della Bitta, Albert J. (1993). Consumer behavior : concepts and applications (4th ed). New York: McGraw-Hill.

Mougayar, W. (1998). Opening Digital Markets. New York: McGraw Hill.

Ngai, E.W.T. \& Wat, F.K.T. (2002). A literature review and classification of electronic commerce research, Information and Management, Vol. 39 No. 5, pp. 415-29.

Nisa, Gita Chairun. (2013). Pengaruh Orientasi Belanja Dan Gender Differences Terhadap Pencarian Informasi Online Dan Belanja Online. Jakarta: UIN Syarif Hidayatullah.

Park, H. \& Burns, Leslie. (2005). Fashion Orientation, Credit Card Use, and Compulsive Buying. Journal of Consumer Marketing. 22. 135-141. 10.1108/07363760510595959.

Phau, Ian \& Woo, Charise. (2008). Understanding compulsive buying tendencies among young Australians : The roles of money attitude and credit card usage. Marketing Intelligence \& Planning. 26. 441-458. 10.1108/02634500810894307.

Priyatno, Duwi. (2013). Mandiri Belajar Analisis Data dengan SPSS. Yogyakarta: Mediakom. 
Putra, A. A. Ngr Bagus Maha \& Kusuma, A. A. G. Agung Artha. (2014). Pengaruh Kecanduan Internet, Daya Tarik Promosi Dan Kepemilikan Kartu Kredit Terhadap Perilaku Pembelian Impulsif Online. Bali: Universitas Udayana.

Ratnasingam, P., \& Pavlou, P. A. (2003). Technology Trust in Internet-Based Interorganizational Electronic Commerce. Journal of Electronic Commerce in Organizations (JECO), 1(1), 17-41. doi:10.4018/jeco.2003010102

Rigopoulos, George. (2019). A TAM Framework to Evaluate Users Perception Towards Online Electronic Payments. Greece: Research Associate, School of Electrical \& Computer Engineering, National Technical University of Athens.

Rook, D. W. (1987). The Buying Impulse. Journal of Consumer Research, 14(2), 189. doi:10.1086/209105.

Rook, D. W., \& Fisher, R. J. (1995). Normative Influences on Impulsive Buying Behavior. Journal of Consumer Research, 22(3), 305. doi:10.1086/209452.

Sedigh, Yalda Danesh. (2013). Development And Validation Of Technology Acceptance Modelling For Evaluating User Acceptance Of An E-Learning Framework. England: The University Of Birmingham.

Sudjana, Nana. (2007). Teknik Analisis Regresi dan Korelasi. Bandung: Tarsito.

Sugiama, A Gima. (2008). Metode Riset Bisnis dan Manajemen. Bandung: CV. Guardaya Intimarta.

Sugiyono. (2013). Metode Penelitian Manajemen Pendidikan Pendekatan Kuantitatif. Bandung: Alfabeta.

Suhartanto, D. (2014). Metode Riset Pemasaran. Bandung: Alfabeta.

Tangke, Natalia. (2004). Analisa Penerimaan Penerapan Teknik Audit Berbantuan Komputer (TABK) Dengan Menggunakan Technology Acceptance Model (TAM) Pada Badan Pemeriksa Keuangan (BPK) RI. Surabaya: Universitas Kristen Petra.

Tarantang, Jefry \& Awwaliyah, Annisa \& Astuti, Maulidia \& Munawaroh, Meidinah. (2019). Perkembangan Sistem Pembayaran Digital Pada Era Revolusi Industri 4.0 Di Indonesia. Jurnal Al-Qardh. 4. 60-75. 10.23971/jaq.v4i1.1442.

Thompson, R.A. (1991). Emotional regulation and emotional development. Educational Psychology Review, 3, 269-307. doi:10.1007/BF01319934

Venkatesh, V., \& Morris, M. (2000). Why Don't Men Ever Stop to Ask for Directions? Gender, Social Influence, and Their Role in Technology Acceptance and Usage Behavior. MIS Quarterly, 24(1), 115-139. doi:10.2307/3250981

Venkatesh, Viswanath \& Davis, Fred. (2000). A Theoretical Extension of the Technology Acceptance Model: Four Longitudinal Field Studies. Management Science. 46. 186-204. 10.1287/mnsc.46.2.186.11926.

Widawati, Lisa. (2011). Analisis Perilaku "Impulse Buying" dan "Locus of Control"pada Konsumen di Carrefour Bandung. Bandung: Universitas Islam Bandung.

Wigand, R. T. (1997). Electronic Commerce: Definition, Theory, and Context. The Information Society, 13(1), 1-16. doi:10.1080/019722497129241.

Zwass, V. (1996). Electronic Commerce: Structures and Issues. International Journal of Electronic Commerce, 1, 3-23. https://doi.org/10.1080/10864415.1996.11518273

Sumber Internet:

Fadila, Annisa. (2020). Pengguna Paylater Naik 14 Kali Lipat. Jakarta: Kontan. https://keuangan.kontan.co.id/news/punya-fitur-paylater-pengguna-gopay-naik-14-kali-lipat diakses pada 10 Juni 2020.

Nabila, Marsya. (2020). Paylater Perusahaan Teknologi Dongkrak Pertumbuhan Kredit Konsumsi. Jakarta: Daily Social. https://dailysocial.id/post/paylater-perusahaan-teknologi-dongkrakpertumbuhan-kredit-konsumsi diakses pada 10 Juni 2020.

Nayoan, Aldwin. (2019). Apa itu Ecommerce? Kenali Semua Jenis dan Manfaatnya. Jakarta: Niaga hoster. https://www.niagahoster.co.id/blog/apa-itu-ecommerce/ diakses pada 10 Juni 2020.

Quiserto, R. (2019). Paylater - OVO, Gojek, Traveloka - Mana Terbaik Terpercaya. Jakarta: Duwitmu. https://duwitmu.com/pinjaman-online/paylater-ovo-gojek-traveloka-terbaik/amp/ diakses pada 10 Juni 2020. 
Setiawan, Rulli. (2020). Aplikasi Paylater Terbaik di Indonesia dan Perkembangannya. Jakarta: Atur Saja. https://www.atursaja.com/609/aplikasi-paylater-terbaik-di-indonesia/ diakses pada $10 \mathrm{Juni}$ 2020.

Wahyuningsih. (2018). Lima Alasan Kenapa Banyak Orang Beralih ke Belanja Online. Jakarta: Cermati. https://www.cermati.com/artikel/5-alasan-kenapa-banyak-orang-beralih-ke-belanjaonline diakses pada 10 Juni 2020.

Walfazri, Maizal. (2019). Jumlah Pengguna Naik 10 Kali Lipat, Traveloka Paylater Tingkatkan Keamanan Pengguna. Jakarta: Kontan. https://industri.kontan.co.id/news/jumlah-pengguna-naik10-kali-lipat-traveloka-paylater-tingkatkan-keamanan-pengguna diakses pada 10 Juni 2020.

Yasmin, Gina Noor Sela Ariella. (2019). Peran Logistik dalam Kemajuan E-Commerce di Indonesia. Jakarta: Artikel Logistrik E-Commerce. https://supplychainindonesia.com/peran-logistik-dalamkemajuan-e-commerce-indonesia diakses pada 10 Juni 2020

*Email korespondensi:

rahmatikasari4@gmail.com 